\title{
The Processing of Ambiguous Verbs in School-Aged Children and Adults
}

\author{
Jung Min Ryu ${ }^{\mathrm{a}}$, Mina Hwang ${ }^{\mathrm{b}}$, Sunhee Ko \\ ${ }^{a}$ Graduate School of Special Education, Dankook University, Yongin, Korea \\ ${ }^{b}$ Department of Special Education, Dankook University, Yongin, Korea \\ ${ }^{c}$ Graduate School of Special Education, Kongju University, Gongju, Korea
}

\section{Correspondence: Sunhee Ko, $\mathrm{PhD}$}

Graduate School of Special Education, Kongju University, 56 Gongjudaehak-ro, Gongju 32588 , Korea

Tel: +82-41-850-8409

Fax: +82-41-850-8410

E-mail: shko@kongju.ac.kr

Received: January 4, 2018

Revised: February 12, 2018

Accepted: February 22, 2018

\begin{abstract}
Objectives: When we read texts, it is necessary to access the meanings of various words. During this process, the meanings related to the context are facilitated, and the meanings unrelated to that context are suppressed. This study investigated whether children differ from young adults in the processing of ambiguous verbs. Methods: This study was conducted with 25 children in 5th to 6th grade and 17 young adults. Response accuracy and reaction time were measured using a sensicality judgment task, where the participant judges if a sentence makes sense, or is nonsense, after reading it. This task was divided into consistent and inconsistent conditions depending on the consistency of meaning of ambiguous verbs in the priming and the target sentences. Results: Both children and adults showed lower accuracy and slower response times in the inconsistent condition than in the consistent condition. Children showed lower accuracy and slower response times than adults in both conditions. Children showed remarkably low accuracy in the inconsistent condition. Conclusion: Children performed poorly compared to adults in reading comprehension, but tended to use contexts to process word meanings like adults. However, they showed difficulty suppressing information irrelevant to the context of sentences. It means that premature suppression ability can cause failures in reading comprehension for children.
\end{abstract}

Keywords: Ambiguous verbs, Context effect, Suppression, Sensicality judgment task
읽기는 지속적인 경험과 교육을 통해 얻어지는 후천적인 산물이 다. 특히, 학령기 아동들에게는 교과 내용을 학습하기 위해 반드시 읽기 기술이 선행되어야 하며, 이들은 학년이 올라갈수록 다양하 고 복잡한 교과 내용을 학습해야 하기 때문에 그에 맞는 읽기 능력 을 갖추는 것이 매우 중요하다(McCray, Vaughn, \& Neal, 2001). 읽 기 이해를 위해서는 하위 과정들이 복잡하게 상호작용하게 되는 데, 이를테면, 글자를 지각하고, 개별 어휘들의 의미를 확인하고, 문 법적인 요소를 파악하고, 개별 문장의 의미를 표상한 후 이들을 통 합하고 재구성함으로써 최종적으로 읽기 이해가 가능해지는 것이 다(Nation, 2008).

이처럼 읽기 이해를 위해서는 다양한 능력들이 요구되지만 이 중에서도 어휘력 및 어휘 의미 처리 능력은 읽기 이해를 위해 기본 이 되며 핵심적인 역할을 하게 된다(Cain \& Oakhill, 2006; Cun- ningham \& Stanovich, 1997; Jeong, 2009a; Joshi \& Aaron, 2000; Nagy \& Scott, 2000; Nation \& Snowling, 1998; Kim \& Hwang, 2008). 어휘 능력은 크게 얼마나 많은 어휘들을 알고 있는가(vocabulary size)와 개별 어휘들에 대해 얼마나 많은 지식을 알고 있는 가(vocabulary knowledge)로 나누어 생각해볼 수 있다. 일반적으 로 아동들의 어휘 능력을 평가하고자 할 때 주로 양적인 평가가 이 루어지고 있기는 하나 읽기 이해를 예측하는 변인을 탐색한 연구 들에서 보면 어휘의 양과 더불어 어휘 지식 또한 읽기 이해를 예측 하는 중요한 변인임을 알 수 있다(Ouellette, 2006; Tannenbaum, Torgesen, \& Wagner, 2006). 선행연구들에서 아동들의 어휘 지식 및 의미 처리 특성을 알아보기 위해서 단어 정의하기, 단어 유추하 기, 다의어 등을 사용하여 왔는데(Jeong, 2009b; Ko, Choi, \& Hwang, 2010; Lee \& Lee, 2007; Shin \& Lee, 2016), 본 연구에서는 다의동사 
를 사용하여 아동들의 어휘 의미 처리 특성을 살펴보고자 하였다.

초등학교 고학년 아동들은 기본적인 언어 기술이 성인 수준에 근접할 만큼 발달하지만 이들이 글을 읽으면서 이해할 때는 여전 히 여러 가지 난관에 봉착하게 된다. 이 중 하나가 다의어의 모호성 을 해소하는 일일 것이다(McNamara \& McDaniel, 2004). 예를 들 어, '다리'는 어떤 문맥과 함께 쓰이냐('다리가 아프다', '다리를 건 넜다')에 따라 그 의미가 달리 해석된다. 더욱이 한국어의 경우 동 사의 대부분이 다의성을 띠고 있어 성공적인 읽기 이해를 위해서는 이들의 의미를 정확히 이해할 필요가 있다(Zoh, 1997). 어휘의 다의 적인 특성은 대부분의 언어에서 나타나는 보편적인 현상이며, 이 를 해소하려는 시도, 즉 문맥을 활용하여 적절하게 의미를 해석하 려는 시도는 언어 처리에 있어 중요한 측면이라 할 수 있다(Rodd, Gaskell, \& Marslen-Wilson, 2002). 이에 본 연구에서는 아동들의 다의동사의 의미 처리 능력을 성인과 비교함으로써 아동들이 성인 들처럼 문맥을 활용하여 다의동사의 의미를 효과적으로 처리하는 지, 이 과정에서 미숙한 점은 무엇인지를 알아보고자 하였다.

아동들이 언어를 처리할 때 문맥을 사용하려는 시도는 이른 나 이에서부터 나타나기 시작하는데, Friedrich와 Friederici (2005)는 event-related brain potential (ERP) 연구를 통해 19개월의 어린 아 동들도 어휘를 처리할 때 문맥을 활용할 수 있음을 확인하였다. 또 한 아동들이 점차적으로 읽기를 학습함에 따라 글을 읽을 때에도 다양한 문맥 단서를 활용하여 새로운 단어의 의미와 속성들을 추 측하게 된다. 초등학생들의 경우 성인처럼 능숙하게 문맥을 활용하 는 수준까지는 미치지 못하지만, 저학년에서 고학년으로 올라가면 서 문맥을 처리하는 능력이 지속적으로 발달한다(Booth, Harasack, \& Burman, 2006). 특히 저학년의 경우 문장 수준의 문맥보다 어휘 수준의 문맥을 사용하는 경향이 있는 반면, 고학년의 경우 성 인과 유사한 방식으로 문장 수준의 문맥을 사용하는 경향이 있다 고 하였다(Khanna \& Boland, 2010). 이 같은 아동들의 문맥 처리 특성을 고려하여 본 연구에서는 고학년 아동들이 성인들처럼 문맥 을 활용하여 다의동사의 의미를 효과적으로 처리하는지를 알아보 고자하였다.

어휘와 관련된 지식들은 읽기 이해를 위해 기본적인 자원으로 활용될 테지만, 실시간으로 빠르게 처리되는 읽기 이해 과정 속에 서 이 같은 어휘 정보를 효율적으로 처리하는 능력, 즉 심성어휘집 (lexicon)에 있는 어휘 정보에 접속하여 인출하고 동시에 활성화된 불필요한 정보를 빠르게 억제하는 능력 또한 읽기 이해를 위해 매 우 중요하다. 글을 읽고 이해하는 과정에서는 흔히 불필요하거나 부적절한 정보들까지 동시에 활성화되는데, 덜 능숙한 독자는 능 숙한 독자에 비해 무시해야하는 정보나 불필요하거나 부적절한 정
보를 빠르게 억제하는 데 어려움이 있고, 이것이 읽기 이해를 저해 하는 요인일 수 있다(Gernsbacher \& Robertson, 1995). 읽기 처리 를 연구한 많은 연구들에서 보면, 관련된 정보들을 빠르게 접속하 는 능력보다는 불필요한 정보를 빠르게 억제하는 능력이 대상자들 의 읽기 이해 능력과 더 밀접한 관계가 있다고 하였다(Gernsbacher \& Faust, 1991; Gernsbacher \& Robertson, 1995; Gernsbacher, Varner, \& Faust, 1990; Khanna \& Boland, 2010). 이에 아동들이 어휘 의 의미를 처리함에 있어 촉진 및 억제 기제를 적절히 사용할 수 있 는지를 알아보기 위하여 다의동사를 활용한 점화 과제(priming task)의 한 형태인 의미 판단 과제(sensicality judgment task)를 사 용하였다.

점화 과제는 무의식적으로 일어나는 내재적인 정보 처리 과정을 알아보기 위한 실험방법으로 어휘 접속이나 구문 처리와 같이 실 시간으로 일어나는 언어 처리 과정을 살펴보기 위해 고안되었다 (Zurif et al., 1993). 이 과제는 점화 자극에 이어 목표 자극을 제시 하고 목표 자극에 대한 정확도와 반응시간을 정교하게 측정하게 된다. 본 연구에서는 점화 과제로 의미 판단 과제를 사용하였는데 이는 구절 또는 문장을 읽고 그에 단어들의 조합이 말이 되는가 되 지 않는가(make sense/nonsense)를 판단하는 과제이다. 본 연구에 서는 다의동사가 포함된 점화 문장과 목표 문장을 제시하고 대상 자들에게 그것이 말이 되는지 말이 안 되는지를 판단하도록 하였 다. 이때 점화 문장과 목표 문장에서는 동일한 다의동사가 사용되 었으나, 의미 일치 조건에서는 점화 문장(예: 화면을 가리다)과 목 표 문장(예: 얼굴을 가리다)의 다의동사가 동일한 의미로 사용되었 고, 의미 불일치 조건에서는 점화 문장(예: 과일을 갈다)과 목표 문 장(예: 전등을 갈다)의 다의동사가 각기 다른 의미로 사용되었다. 의미 일치 조건에서는 점화 문장을 처리하면서 이미 활성화된 다의 동사의 의미를 목표 문장의 의미 처리에 적용하면 되기 때문에 반 응촉진 효과가 나타날 것으로 기대되는 반면, 의미 불일치 조건에 서는 점화 문장에서 활성화된 다의동사의 의미를 빠르게 억제하고 목표 문장에서 사용된 다의동사의 또 다른 의미를 접속해야 하기 때문에 의미 일치 조건과는 다른 의미 처리 과정이 요구될 것이다 (Klein \& Murphy, 2001).

종합하여보면, 아동은 어린 시절부터 어휘학습을 위하여 문맥 을 활용하고 연령이 증가함에 따라 그 능력을 발전시켜 간다. 글을 이해하는 과정에서는 다양한 의미 정보들을 탐색하게 되는데 이때 문맥과 관련이 있는 의미는 촉진하고 관련이 없는 의미는 억제하 는 과정을 거치게 된다. 따라서 본 연구에서는 의미 판단 과제를 활 용하여 점화 문장과 목표 문장의 다의동사의 의미가 일치하는 조 건과 불일치하는 조건에서 반응정확도와 반응속도를 측정하여 고 
학년 아동이 다의동사의 의미를 처리함에 있어 성인과 어떠한 차 이를 보이는지를 살펴보고자 하였다. 이는 아동들의 의미 처리 및 읽기 이해 특성을 이해하는 데 도움이 될 것이며, 더 나아가서 읽기 이해 부진 아동들이나 덜 숙련된 독자들의 읽기 이해 특성을 이해 하고 이들에 대한 지속적으로 연구를 위해 기초적인 자료를 제공 할 것이다.

\section{연구방법}

\section{연구대상}

본 연구의 대상은 서울, 경기 지역에 거주하는 초등학교 5,6 학년 아동 25 명과 성인 17 명, 총 42 명이었다. 아동들의 경우, (1) 부모 또 는 교사에 의해 지적 능력의 결함이 의심되지 않는다고 보고되었으 며, (2) 국립특수교육원 기초학력검사(Korean Institute for Special Education-Basic Academic Achievement Tests, KISE-BAAT; Park, Kim, Song, Jung, \& Jung, 2008)의 읽기검사 중 짧은 글 이해에서 $80 \%$ ile 이상에 위치하며, (3) 기질적 장애, 정서장애, 행동장애, 감각 장애가 없는 아동으로 선정하였다. 선정된 아동은 남자 8명, 여자 17 명이고, 이 중 5 학년이 15 명, 6 학년이 10 명이었다. 본 연구에 참여 한 아동들의 학년별 KISE-BAAT 결과는 Table 1과 같다.

성인의 선정기준은 다음과 같다. (1) 현재 대학에 재학 중이거나 대학을 졸업하였고, (2) 연령이 20-32세 사이이며, (3) 기질적 장애, 정서장애, 행동장애, 감각장애가 없는 자로 선정하였다. 선정된 대 상은 남자 8 명, 여자 9 명이었다.

\section{연구도구}

본 연구에서는 아동과 성인의 다의동사 이해 특성을 살펴보고 자 Klein과 Murphy (2001)의 과제를 참고하여 의미 판단 과제를 제 작하였다. 이 과제의 각 문항은 동일한 다의동사가 포함된 점화 문 장과 목표 문장으로 구성되어 있고 대상자들은 점화 문장과 목표 문장 각각에 대해 그 의미성을 판단하여 ‘예' 또는 ‘아니오'로 답하 게 된다. 이때 점화 문장과 목표 문장에서 쓰인 다의동사의 의미가

Table 1. Children's characteristics

\begin{tabular}{lcc}
\hline & Children (N=25) & Young adults (N=17) \\
\hline Age (yr) & $11.52(.43)$ & $22.76(3.22)$ \\
KISE-BAAT (reading comprehension) & & \\
Raw score & $21.67(2.21)$ & - \\
\%ile & $92.99(6.00)$ & -
\end{tabular}

Values are presented as mean (SD).

KISE-BAAT = Korean Institute for Special Education-Basic Academic Achievement Tests (Park, Kim, Song, Jung, \& Jung, 2008).
일치하는 조건(이하 의미일치조건)과 점화 문장과 목표 문장에서 쓰인 다의동사의 의미가 불일치하는 조건(이하 의미불일치조건)으 로 나뉜다.

이 같은 과제를 제작하기 위하여 다의동사를 우선 선정하였는데 그 기준은 다음과 같다. (1) 표준국어대사전(National Institute of the Korean Language, 1999)에 등재된 다의어 중 2-3음절 이내의 동사이고, (2) Kim (2003)의 등급별 국어교육용 어휘를 참고하였 을 때 3등급 이내의 낱말이며, (3) 초등학교 교과서 어휘 조사 연구 (Kim, 2009)에 등재된 다의동사 중 두 의미의 사용 빈도 차이가 적 게 나는 낱말이다. 이 같은 기준으로 80 개의 다의동사를 선정하였다. 이들 80 개의 다의동사에 대해서는 각각 그 다의동사가 포함된 2 개의 2 어절 문장을 제작하였다. 본 과제를 의미일치조건과 의미불 일치조건으로 나누기 위하여 이 중 40 개의 다의동사에 대해서는 다의동사가 같은 의미로 사용된 두 개의 문장을 만들었고(예: 거울 을 깨다/ 창문을 깨다), 나머지 40 개의 다의동사에 대해서는 다의 동사의 의미가 각기 다르게 쓰인 2 개의 문장을 만들었다(예: 끈을 매다/ 밭을 매다).

이렇게 제작된 문항들은 언어치료를 전공하고 있는 6 명의 석사 과정 학생들을 통해 다의어의 의미가 적절하게 쓰였는지를 검증받 았다. 또한 의미일치조건에서 두 문장의 의미가 실제로 비슷한지, 의미불일치조건에서 두 문장의 의미가 불일치하는지를 5점 척도 (전혀 다름, 조금 다름, 보통, 조금 비슷, 매우 비슷)로 평가하여 6명 중 5 명 이상에서 매우 비슷함 또는 매우 다름으로 평가된 의미일치 조건 30 문항과 의미불일치조건 30 문항을 선정하였다. 이들 60 문항 을 우선 의미 판단 과제로 만들어 대학생 10 명에게 예비실험을 하 여 문장 판단의 정확도와 반응속도를 측정한 후 정확도가 높은 순 서대로 최종 의미일치조건 20 문항과 의미불일치조건 20 문항을 선 정하였다. 이들 각 조건에서의 20 문항 중 2 개는 연습문항으로 18 개 는 본 문항으로 최종 제작되었으며, 각 조건에 따른 문항의 예는 Appendix 1과 같다.

본 문항에 대해 의미성을 판단하였을 때 모두 ‘예’ 반응을 해야 하기 때문에 ‘아니오' 반응을 이끌어 내기 위한 문항(foils) 39 개를 제작하였다. 점화 문장이 의미성이 있고, 목표 문장은 의미성이 없 는 문항 13 개, 반대로 점화 문장은 의미성이 없고 목표 문장은 의미 성이 있는 문항 13 개, 마지막으로 점화 문장과 목표 문장 모두 의미 성이 없는 문항 13 개이다. 채우기 문항을 위해서는 모두 비다의동 사를 사용하였다. 채우기 문항의 예는 Appendix 2와같다.

\section{연구절차}

본 실험을 위해 과제는 E-PRIME version 2.0을 사용하여 제작 
하였으며 실험을 위해 노트북(SAMSUNG NT300E5C)을 사용하 였다.

과제 수행에 앞서 검사자는 대상자에게 다음과 같이 설명하였다. "먼저 컴퓨터 화면에 십자가 모양이 잠깐 나타날 거예요. 이건 화면 에 집중하라는 뜻이에요. 그리고 십자가 모양이 사라지면 2개의 낱 말로 된 문장이 나올 거예요. 이 문장을 정확하게 읽은 다음에 그 문장이 말이 되는지 안 되는지를 생각해 보고, 말이 된다고 생각하 면 ‘예’ 버튼을 누르고, 말이 안 된다고 생각하면 ‘아니오' 버튼을 누 르면 되는 거예요." 그리고 이어서 ‘불씨가 걸어요’라는 문장을 예 를 들어서 왜 말이 되지 않는지를 설명하여 주었다. 본 과제를 수행 하기에 앞서 아동들에게 12 문항의 연습 문항을 풀도록 하고 그 결 과에 대한 피드백을 준 후 대상자들이 과제를 충분히 이해했다고 판단된 경우 본 과제를 실시하였다. 본 과제는 다음과 같은 절차로 진행이 된다. 첫 화면에 '준비되면 SPACE BAR를 눌러 주세요라는 화면이 나오고 대상자가 이에 반응하면 화면 중앙에 '+'가 $500 \mathrm{~ms}$ 나타났다 사라진 후 점화 문장이 제시된다. 대상자는 이를 읽고 빠 르게 의미성 여부를 판단하여 '예/아니오' 버튼을 누르게 된다. 대 상자들이 버튼을 누르면 점화 문장이 사라지고 빈 화면이 $500 \mathrm{~ms}$ 제시된 후 목표 문장이 나온다. 대상자는 이에 대해 문장의 의미성 여부를 판단하여 ‘예/아니오' 버튼을 누르게 된다. 대상자가 목표 문장에 대해 버튼을 누르면 한 문항이 끝나게 되고 $1,000 \mathrm{~ms}$ 후에 같은 절차로 다음 문항이 제시된다(Figure 1).

\section{자료 분석}

채우기 문항 39 개는 본 자료 분석에서 제외되었으며, 다의동사가 사용된 의미일치조건의 18 문항과 의미불일치조건의 18 문항만을 분석하였다. 점화 문장과 목표 문장 모두에 대해 '예’로 반응한 것 을 정반응으로 보고 의미 판단 정확도를 산출하였으며, 정확하게 의미를 파악한 문항에 대해 목표 문장의 의미성 판단 반응시간을 분석하였다. 목표 문장 판단의 반응시간은 문장이 화면에 제시되 고 대상자들이 버튼을 누르는 시간까지를 $\mathrm{ms}$ 단위로 측정하였다. 반응시간에 대해 분석하기에 앞서 정반응의 반응시간이 $250 \mathrm{~ms}$ 이 하이거나 반응시간이 각 대상자의 평균 반응시간의 $2 \mathrm{SD}$ 이상인 경우는 부주의 반응으로 간주하고 분석에서 제외하였다(Ratcliff,

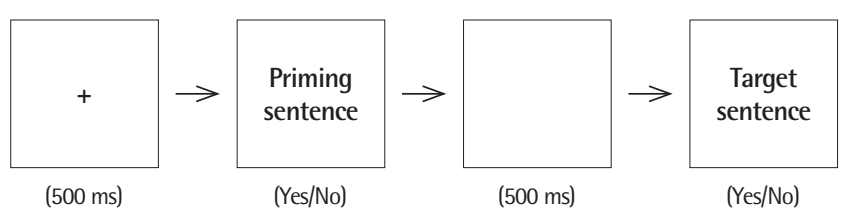

Figure 1. Process of sensicality judgment task.
1993).

아동과 성인이 점화 문장과 목표 문장의 다의동사 의미 일치 여 부에 따라 목표 문장 의미 판단의 정확도와 반응시간에 차이가 있 는지를 알아보고자 집단(2) $\times$ 의미성 일치 여부(2) 이원분산분석 설계를 하였고, 의미 일치 여부 조건은 반복 측정되었다. 자료의 통 계처리는 SPSS version 18.0 for Windows 프로그램을 사용하였다.

\section{연구결과}

아동과 성인의 점화 문장과 목표 문장의 다의동사 의미 일치 여 부에 따른 목표 문장 의미 판단 정확도와 반응시간에 대한 기술통 계 결과는 Table 2 와 같다. 아동들의 경우 의미일치조건에서 정확 도 $91.55 \%$, 반응시간 $1,063.59 \mathrm{~ms}$ 이었으며, 의미불일치조건에서 정 확도 $75.78 \%$, 반응시간 $1,220.07 \mathrm{~ms}$ 이었다. 성인들의 경우 의미일치 조건에서 정확도 $98.69 \%$, 반응시간 $694.88 \mathrm{~ms}$ 이었고, 의미불일치 조건에서 정확도 $92.16 \%$, 반응시간 $804.95 \mathrm{~ms}$ 이었다. 아동들의 경 우 성인들과 비교했을 때 의미불일치조건에서 정확도가 눈에 띄게 낮았고, 아동들이 성인보다 두 조건 모두에서 반응시간이 느렸으 며, 두 집단 모두 의미일치조건에 비해 의미불일치조건에서 느린 반 응을 보였다. 이 같은 기술통계 결과가 유의미한지를 알아보기 위 해 의미 판단 과제의 반응정확도와 반응시간 각각에 대한 이원분 산분석을 실시하였다.

아동과 성인 간 점화 문장과 목표 문장의 다의동사 의미 일치 여 부에 따른 의미 판단 정확도에 차이가 있는지를 알아보고자 이원분 산분석을 시행하였다(Table 3). 그 결과, 집단간주효과 $\left(F_{(1,40)}=42.046\right.$, $p<.001)$, 의미일치 여부에 따른 주효과 $\left(F_{(1,40)}=53.603, p<.001\right)$ 가 유의미하였고, 집단과 의미일치 여부의 상호작용 효과 $\left(F_{(1,40)}=9.189\right.$, $p<.05)$ 또한 유의미하였다. 상호작용 효과를 증명하고자 각 집단 의 의미일치조건과 의미불일치조건의 정확도 차에 대한 $t$-검정을 실시한 결과 집단 간 차이가 유의미하였다 $(t=-3.481, p<.001)$. 이 는 아동들이 성인들에 비해 의미가 불일치조건에서 목표 문장의

Table 2. Accuracy and reaction time in sensicality judgment task

\begin{tabular}{lcc}
\hline & Children (N=25) & Young adults (N=17) \\
\hline Consistent condition & & \\
Accuracy (\%) & $91.55(6.03)$ & $98.69(3.12)$ \\
Reaction time (ms) & $1,063.59(269.56)$ & $694.88(167.81)$ \\
Inconsistent condition & & \\
Accuracy (\%) & $75.78(10.86)$ & $92.16(6.53)$ \\
Reaction time (ms) & $1,220.07(309.47)$ & $804.95(150.51)$ \\
\hline
\end{tabular}

Values are presented as mean (SD). 
Table 3. Results of two-way ANOVA on accuracy in sensicality judgment task

\begin{tabular}{lrrrc}
\hline Source & $\begin{array}{c}\text { Type III sum } \\
\text { of squares }\end{array}$ & $d f$ & Mean square & $F$ \\
\hline Between group & & & & \\
$\quad$ Group & $2,797.939$ & 1 & $2,797.939$ & $42.046^{* * *}$ \\
$\quad$ Error & $2,661.781$ & 40 & 66.545 & \\
Within group & & & & \\
$\quad$ Condition & $2,518.908$ & 1 & $2,518.908$ & $53.603^{* * *}$ \\
Condition $\times$ Group & 431.834 & 1 & 431.834 & $9.189^{*}$ \\
Error & $1,879.683$ & 40 & 46.992 & \\
\hline
\end{tabular}

${ }^{*} p<.05,{ }^{* * *} p<.001$.

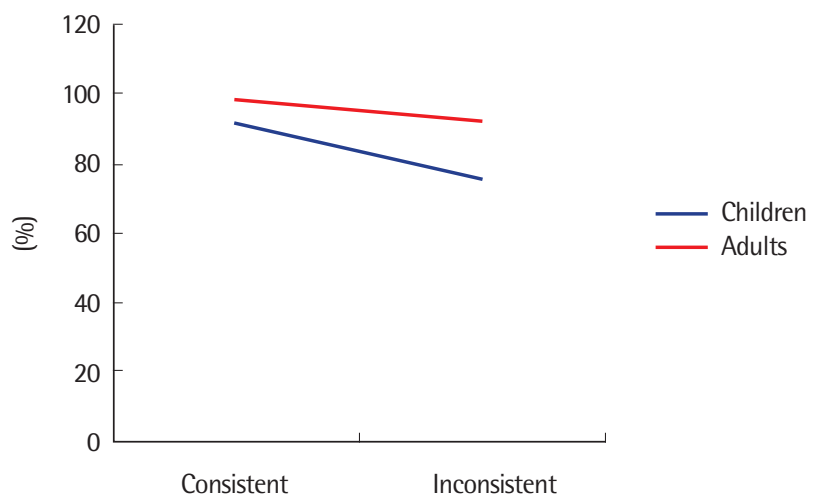

Figure 2. Accuracy of children and young adults depending on condition.

의미를 판단하는 데 더욱 어려움을 보인 것으로 해석된다(Figure 2)

아동과 성인 간 점화 문장과 목표 문장의 다의동사 의미 일치 여 부에 따른 의미 판단 반응시간에 차이가 있는지를 알아보고자 이원 분산분석을 시행하였다(Table 4$)$. 그 결과, 집단 간 주효과 $\left(F_{(1,40)}=\right.$ $27.577, p<.001)$, 의미 일치 여부에 따른 주효과 $\left(F_{(1,40)}=41.493, p<\right.$ .001)가 유의미하였으나, 집단과 의미 일치 여부의 상호작용 효과는 유의미하지 않았다(Figure 3).

\section{논의 및 결론}

본 연구에서는 아동들이 성인들처럼 어휘의 의미 처리를 위해 문맥을 활용할 수 있는지 그리고 문맥과 부합되지 않은 정보를 억 제할 수 있는지를 알아보고자 하였다. 이를 위해 5-6학년 아동과 성인을 대상으로 의미 판단 과제를 사용하여 점화 문장과 목표 문 장에 쓰인 다의동사의 의미 일치 여부에 따른 정확도와 반응시간 을 측정하였다. 그 결과, 아동들과 성인들 모두 의미일치조건에서보 다 의미불일치조건에서 낮은 정확도와 느린 반응속도를 보였고, 아 동들이 성인들에 비해 모든 조건에서 반응정확도가 낮았고 반응
Table 4. Results of two-way ANOVA on reaction time in sensicality judgment task

\begin{tabular}{lrrrr}
\hline Source & $\begin{array}{c}\text { Type III sum of } \\
\text { squares }\end{array}$ & $d f$ & Mean square & $F$ \\
\hline Between group & & & & \\
$\quad$ Group & $3,108,563.683$ & 1 & $3,108,563.683$ & $27.577^{* * *}$ \\
$\quad$ Error & $4,508,875.086$ & 40 & $112,721.877$ & \\
Within group & & & & \\
Condition & $359,496.588$ & 1 & $359,496.588$ & $41.493^{* * *}$ \\
Condition×Group & $10,897.781$ & 1 & $10,897.781$ & 1.258 \\
Error & $346,557.320$ & 40 & $8,663.933$ & \\
\hline
\end{tabular}

${ }^{* * *} p<.001$

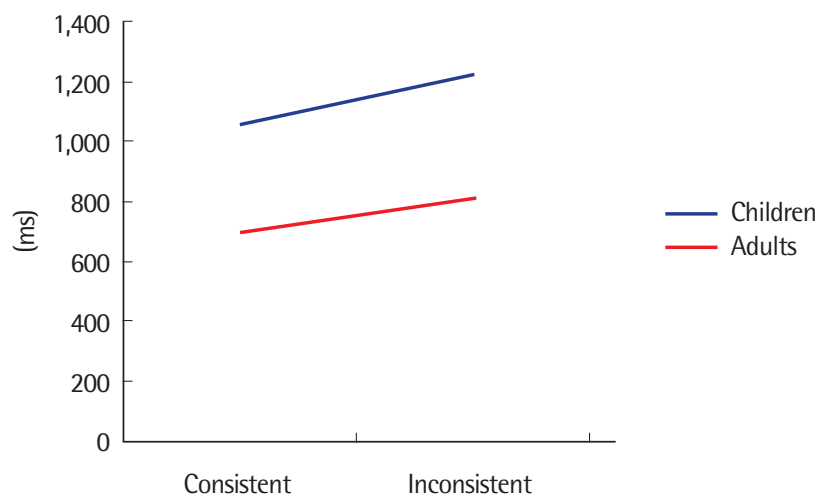

Figure 3. Reaction time of children and young adults depending on condition.

속도도 느렸다. 그러나 아동들의 경우 유독 의미불일치조건에서 반 응정확도가 성인에 비해 현저히 낮아짐을 확인할 수 있었다. 이 같 은 결과에 대한 논의는 다음과 같다.

첫째, 아동들의 경우 점화 문장과 목표 문장을 읽고 그 의미성 여 부를 판단하는 데 있어 정확도나 반응시간 전반에 걸쳐 성인에 미 치지 못하는 수행을 보였다. 읽기 이해는 수년간의 경험과 학습을 통해 숙달되고 축적되는 능력이기에 아동들이 성인에 미치지 못하 는 수행을 보이는 것이 특이한 점은 아닐 것이다. 그러나 본 과제에 서 사용한 다의동사들은 고학년 아동들이라면 그 의미들을 이미 습득했을 것으로 간주되는 어휘들이었기에 아동들이 성인보다 저 조한 수행을 보인 것은 단순히 다의동사에 대한 어휘 지식이 부족 하기 때문이 아니라 문맥을 활용하여 다의동사의 의미를 효율적이 고 정확하게 처리하는 데 있어 성인보다 저조했기 때문으로 해석해 야 할 것이다. 또한, 문장의 의미를 판단하기 위해서는 개별 단어의 의미를 파악하고 문맥에 비추어 적절한 의미를 선택하고 최종적으 로 문장의 의미를 해석해야 하는데, 작업기억 능력이 아직 성인의 수준에 도달하지 못하는 아동들의 경우 이 같은 전반에 걸친 읽기 이해 과정에서 성인보다 미숙했을 수 있다. 선행연구에서 성인의 작 
업기억의 개인차가 다의어 의미 처리와 높은 상관이 있음을 보여주 고 있기에 이 같은 해석도 가능할 것이다(Lee, 2002).

둘째, 아동들이 성인만큼 빠르고 정확하게 문장을 읽고 의미를 파악하는 데는 어려움이 있다 하더라도 아동들 역시 성인과 마찬 가지로 문맥을 활용하여 어휘의 의미를 처리할 수 있었다. 한국어 의 어순으로 볼 때 일반적으로 동사는 문장의 마지막에 위치하기 때문에 동사의 앞쪽에 위치한 문맥을 처리하면서 후행하는 동사의 의미를 미리 좁혀 놓게 되는데(Morris, 1994), 이 같은 문맥처리 능 력이 발달하면서 읽기 이해의 효율성이 증대되는 것이다. 본 과제 에서 점화 문장과 목표 문장에서 사용된 다의동사의 의미가 일치 할 때 아동들 역시 목표 문장을 처리하는 데 촉진 효과가 나타났는 데, 이는 점화 문장을 처리하면서 다의동사의 의미를 문맥에 맞는 의미로 처리하고 그렇게 활성화된 다의동사의 의미를 목표 문장의 의미를 처리하는 데도 적용하였기 때문이다(Klein \& Murphy, 2001).

셋째, 아동과 성인 모두 점화 문장과 목표 문장에서 다의동사의 의미가 불일치할 때 그 의미를 판단하는 데 상대적으로 어려움을 보였다. 앞서 언급한 바와 같이 점화 문장을 읽으면서 다의동사의 의미를 문맥에 적합한 하나의 의미로 특정하고, 그 의미의 활성도 가 낮아지기 전에 목표 문장을 접하게 된다. 이때 목표 문장의 문맥 을 통해 다의동사가 점화 문장에서와는 다른 의미로 쓰였다는 것 을 인지하면서 이미 활성화된 다의동사의 의미를 빠르게 억제하고 다의동사의 다른 의미를 인출하여 문맥에 적용해야 한다. 이 같은 과정에서 가장 중요한 능력은 불필요한 의미 정보를 억제하는 능력 일 것이다. 아동과 성인 모두 불일치 조건에서 정확도가 낮아지고 반응시간이 느려지는 것은 이러한 억제 기제가 발동했다는 것에 대 한 반증일 것이다.

넷째, 아동의 경우 점화 문장과 목표 문장에서 다의동사의 의미 가 불일치할 때 의미 정확도가 유독 낮아지는 경향을 보였다. 아동 들은 점화 문장을 처리하는 과정에서 이미 활성화되어있는 다의동 사의 의미를 억제하지 못하여 목표 문장을 읽는 동안 다의동사의 또 다른 의미로 접속하는 것에 깊이 방해를 받는 것으로 보이며, 이 것이 목표 문장의 이해 실패를 야기하는 것이다. 이 같은 결과로 보 아, 아동들이 성인에 비해 읽은 내용을 이해하는 데 있어 단순히 속 도만 느린 것이 아니라 읽은 내용 자체를 이해하는 데도 어려움을 보일 수 있음을 시사한다. Gernsbacher과 Faust (1991)는 일반적으 로 글을 이해하는 과정에서 문맥과 같은 의미로 쓰인 어휘 혹은 문 장은 촉진하고, 다르게 쓰인 의미는 억제하는 과정을 거치는데, 읽 기 이해에서 발생하는 개인차는 촉진보다는 억제 기제에서 비롯되 어 문맥과 불일치하는 의미를 효율적으로 억제하는 것이 중요하다 고 하였다. 이를 고려하여 볼 때, 아동들이 성인에 비해 읽기 이해에
어려움을 보이는 것은 단순히 문맥을 활용하는 능력이 저조하기 때문이기보다 문맥을 활용하는 과정에서 불필요한 정보를 억제하 는 능력의 저조함 때문으로 설명할 수 있다.

연구결과들을 종합하여 보면, 아동들은 성인과 비교하여 전반 적으로 읽기 이해 능력이 미숙하기는 하나 문맥을 활용하여 모호 성을 해소하려는 경향에 있어서는 성인과 유사한 패턴을 보이지만, 불필요한 정보를 억제하는 데는 상대적으로 어려움을 보이고 이 같은 특성이 아동들의 읽기 이해의 실패 원인이 되는 것으로 보인 다. 결과적으로 아동들은 연령이 증가함에 따라 다양한 읽기 경험 을 축적하고, 작업 기억과 같은 인지처리 능력이 발달하면서 성인 의 읽기 이해 수준에 도달하는 것으로 보인다. 본 연구에서는 정상 아동과 성인을 대상으로 다의동사의 의미 처리 특성을 살펴보았으 나 이를 확장하여 해석하면 읽기이해부진 아동이나 덜 숙련된 독 자들의 읽기 이해의 어려움을 보이는 원인을 이해하는 데 도움이 될 것이다.

본 연구의 과제는 선행문장과 후행문장에 대한 의미 관계를 파 악하도록 하여 읽기 이해에 인위적인 부담을 주는 것이 아니라 각 각에 대한 의미성을 판단하도록 하여 자연스러운 읽기 과정에서 어 휘처리 특성을 살펴보았다는 점에서 기존 연구와 차이가 있으며, 또한 아동들의 읽기 이해 특성을 밝히기 위해 기존에 사용되었던 오프라인(off-line) 과제들이 아닌(Jeong, 2009b; Kim, Kim, \& Kim, 2012; Lee, Hwang, \& Ko, 2017) 온라인(on-line) 과제를 사용하여 실시간으로 의미를 처리하는 과정을 살펴보았다는 점에서 의의가 있다. 그러나 초등학교 고학년 아동들과 성인 두 집단 간 비교를 하 여 다양한 연령의 집단에서 다의동사 처리를 동시에 살펴보지 못 한 것은 본 연구의 제한점이 될 것이다. 이후 본 연구결과를 기초로 언어 연령을 확대하거나 읽기 이해에 어려움을 보이는 아동들을 대상으로 관련 연구가 이루어진다면 아동들의 읽기 이해 및 의미 처리 특성을 이해하는 데 도움이 될 것이다.

\section{REFERENCES}

Booth, J. R., Harasaki, Y., \& Burman, D. D. (2006). Development of lexical and sentence level context effects for dominant and subordinate word meanings of homonyms. Journal of Psycholinguistic Research, 35, 531-554.

Cain, K., \& Oakhill, J. (2006). Profiles of children with specific reading comprehension difficulties. British Journal of Educational Psychology, 76, 683696.

Cunningham, A. E., \& Stanovich, K. E. (1997). Early reading acquisition and its relation to reading experience and ability 10 years later. Developmental 
Psychology, 33, 934-945.

Friedrich, M., \& Friederici, A. D. (2005). Semantic sentence processing reflected in the event-related potentials of one-and two-year-old children. Neuroreport, 16, 1801-1804.

Gernsbacher, M. A., \& Faust, M. E. (1991). The mechanism of suppression: a component of general comprehension skill. Journal of Experimental Psychology: Learning, Memory, and Cognition, 17, 245.

Gernsbacher, M. A., \& Robertson, R. R. (1995). Reading skill and suppression revisited. Psychological Science, 6, 165-169.

Gernsbacher, M. A., Varner, K. R., \& Faust, M. E. (1990). Investigating differences in general comprehension skill. Journal of Experimental Psychology: Learning, Memory, and Cognition, 16, 430-445.

Jeong, M. (2009a). Predictors of poor comprehenders' reading comprehension in 3 to 6 grades (Doctoral dissertation). Dankook University, Yongin, Korea.

Jeong, M. (2009b). Verbal analogical reasoning skills in poor comprehenders. Korean Journal of Communication \& Disorders, 14, 275-287.

Joshi, R. M., \& Aaron, P. G. (2000). The component model of reading: simple view of reading made a little more complex. Reading Psychology, 21, 85-97.

Khanna, M. M., \& Boland, J. E. (2010). Children's use of language context in lexical ambiguity resolution. The Quarterly Journal of Experimental Psychology, 63, 160-193.

Kim, A. H., \& Hwang, M. (2008). Prediction of reading skills in upper elementary students. Korean Journal of Communication \& Disorders, 13, 1-25.

Kim, A. H., Kim, E. J., \& Kim, U. J. (2012). Vocabulary of elementary students: vocabulary accuracy and error patterns in an antonym and synonym test. Curriculum and Instruction Research, 16, 799-813.

Kim, H. S. (2009). Research on elementary school textbook vocabulary. Seoul: National Institute of Korean Language.

Kim, K. (2003). Vocabularies for different levels of Korean education. Seoul: Pagijung.

Klein, D. E., \& Murphy, G. L. (2001). The representation of polysemous words. Journal of Memory and Language, 45, 259-282.

Ko, S., Choi, K. S., \& Hwang, M. (2010). Comprehension of ambiguous words in children with poor reading comprehension. Korean Journal of Communication Disorders, 15, 348-356.

Lee, B. T. (2002). Individual differences in lexical ambiguity resolution: contextdependent processing of skilled readers (Doctoral dissertation). Seoul University, Seoul, Korea.

Lee, M. R., Hwang, M. A., \& Ko, S. H. (2017). Comprehension of polysemous verbs in school-aged children with borderline intelligence. Journal of Speech-
Language and Hearing Disorder, 26, 55-65.

Lee, S. B., \& Lee, H. R. (2007). Definitional category analysis of ambiguous words in Korean children with specific language impairment. Journal of Speech and Hearing Disorders, 16, 1-18.

McCray, A. D., Vaughn, S., \& Neal, L. V. I. (2001). Not all students learn to read by third grade: middle school students speak out about their reading disabilities. The Journal of Special Education, 35, 17-30.

McNamara, D. S., \& McDaniel, M. A. (2004). Suppressing irrelevant information: knowledge activation or inhibition? Journal of Experimental Psychology: Learning, Memory, and Cognition, 30, 465-482.

Morris, R. K. (1994). Lexical and message-level sentence context effects on fixation times in reading. Journal of Experimental Psychology: Learning, Memory, and Cognition, 20, 92-103

Nagy, W. E., \& Scott, J. A. (2000). Vocabulary processes. Handbook of Reading Research, 3, 269-284.

Nation, K. (2008). Learning to read words. Quarterly Journal of Experimental Psychology, 61, 1121-1133.

Nation, K., \& Snowling, M. J. (1998). Semantic processing and the development of word-recognition skills: evidence from children with reading comprehension difficulties. Journal of Memory and Language, 39, 85-101.

National Institute of the Korean Language. (1999). Standard Korean dictionary. Seoul: Author.

Ouellette, G. P. (2006). What's meaning got to do with it: the role of vocabulary in word reading and reading comprehension. Journal of Educational Psychology, 98, 554-566.

Park, G., Kim, G., Song, Y., Jung, D., \& Jung, I. (2008). Korea Institute for Special Education-Basic Academic Achievement Test (KISE-BAAT). Ansan; Korea Institute for Special Education.

Ratcliff, R. (1993). Methods for dealing with reaction time outliers. Psychological Bulletin, 114, 510-532.

Rodd, J., Gaskell, G., \& Marslen-Wilson, W. (2002). Making sense of semantic ambiguity: semantic competition in lexical access. Journal of Memory and Language, 46, 245-266.

Shin, M. J., \& Lee, H. R. (2016). Flexible word definition of school-aged children with specific language impairment. Communication Sciences \& Disorders, 21, 111-120.

Tannenbaum, K. R., Torgesen, J. K., \& Wagner, R. K. (2006). Relationships between word knowledge and reading comprehension in third-grade children. Scientific Studies of Reading, 10, 381-398.

Zoh, M. H. (1997). Working memory and individual differences in reading 
comprehension. Korean Journal of Psychology: General, 16, 18-39.

Zurif, E., Swinney, D., Prather, P., Solomon, J., \& Bushell, C. (1993). An on- line analysis of syntactic processing in broca's and wernicke's aphasia. Brain and Language, 45, 448-464. 
Appendix 1. Examples of items of semantic judgment task

\begin{tabular}{llll}
\hline 조건 & 다의동사 & \multicolumn{1}{c}{ 점화 문장 } & \multicolumn{1}{c}{ 목표 문장 } \\
\hline 의미일치조건 & 가리다 & 화면을 가리다 & 얼굴을 가리다 \\
& 지다 & 내기에 지다 & 시합에 지다 \\
& 돌리다 & 어깨를 돌리다 & 고개를 돌리다 \\
& 개다 & 수건을 개다 & 이불을 개다 \\
& 빼다 & 못을 빼다 & 책을 빼다 \\
의미불일치조건 & 갈다 & 과일을 갈다 & 전등을 갈다 \\
& 타다 & 햇볕에 타다 & 택시를 타다 \\
& 말리다 & 빨래를 말리다 & 싸움을 말리다 \\
& 켜다 & 기지개를 켜다 & 형광등을 켜다 \\
& 매다 & 끈을 매다 & 밭을 매다 \\
\hline
\end{tabular}

Appendix 2. Examples of foils of semantic judgment task

\begin{tabular}{lccc}
\hline 조건 & 비다의동사 & 점화 문장 & 목표 문장 \\
\hline 예-아니오 & 가꾸다 & 꽃을 가꾸다 & 책을 가꾸다 \\
아니오-예 & 뽑다 & 아침을 뽑다 & 이빨을 뽑다 \\
아니오-아니오 & 않다 & 우물을 않다 & 바다를 않다 \\
\hline
\end{tabular}




\section{국문초록}

\section{문맥에 따른 학령기 아동과 성인의 다의동사 의미 처리 특성 \\ 류정민 ${ }^{1}$ 황민아 $\cdot$ 고선희 ${ }^{3}$ \\ 1단국대학교 특수교육대학원, ${ }^{2}$ 단국대학교 특수교육과, ${ }^{3}$ 공주대학교 특수교육대학원}

배경 및 목적: 글을 이해하기 위해서는 다양한 의미 정보들을 탐색하게 되는데, 이때 문맥과 관련이 있는 의미는 촉진하고 관련이 없는 의미는 억제하는 과정을 거치게 된다. 따라서 본 연구에서는 고학년 아동들이 다의동사의 의미를 처리함에 있어 성인과 어떠한 차이를 보이는지 알아보고자 하였다. 방법: 본 연구는 초등학교 5-6학년 아동 25명과 성인 17명을 대상으로 하였다. 의미 판단 과제를 사용하 여 다의어가 포함된 점화 문장과 목표 문장이 말이 되는지 여부를 판단하도록 하여 반응정확도와 반응시간을 측정하였다. 이 과제는 점화 문장과 목표 문장에 포함된 다의동사가 같은 의미로 사용된 의미일치조건과 점화 문장과 목표 문장에 포함된 다의동사가 다른 의 미로 사용된 의미불일치조건으로 나뉜다. 결과: 아동들과 성인들 모두 의미일치조건보다 의미불일치조건에서 낮은 정확도와 느린 반 응속도를 보였고, 아동들이 성인에 비해 모든 조건에서 낮은 정확도와 느린 반응속도를 보였다. 그러나아동들의 경우 유독 의미불일치 조건에서의 반응정확도가 성인에 비해 현저히 낮아짐을 확인할 수 있었다. 논의 및 결론: 아동들은 성인과 비교하여 전반적으로 읽기 이해 능력이 미숙하기는 하지만 문맥을 활용하여 의미를 처리하려는 경향은 성인과 유사한 패턴을 보이는 반면 문맥과 관련이 없는 불 필요한 정보를 억제하는 데는 상대적으로 어려움을 보이는데 이 같은 특성이 아동들의 읽기 이해 실패의 원인이 될 것이다.

핵심어: 다의동사, 문맥 효과, 억제, 의미 판단 과제

\section{참고문헌}

고선희, 최경순, 황민아(2010). 읽기이해부진 아동의 다의어 의미처리 특성. 언어청각장애연구, 15, 348-356.

국립국어원(1999). 표준국어대사전. 서울: 국립국어원.

김광해(2003). 등급별 국어교육용 어휘. 서울: 박이정.

김애화, 김은주, 김의정(2012) 초등학생의 어휘특성 연구: 반대말과 비슷한 말 검사를 통한 어휘발달 패턴 및 오류 유형 분석. 교과교육학연구, 16 , 799-813.

김애화, 황민아(2008). 초등학교 고학년의 읽기능력에 영향을 미치는 읽기관련변인에 관한 연구. 언어청각장애연구, 13, 1-25.

김한샘(2008). 초등학교 교과서 어휘 조사 연구. 서울: 국립국어원.

박경숙, 김계옥, 송영준, 정동영, 정인숙(2008). 기초학력검사(Korea Institute for Special Education-Basic Academic Achievement Test, KISE-

BAAT). 안산: 국립특수교육원.

신문자, 이희란(2016). 학령기 단순언어장애 아동의 동음이의어 정의하기. 언어청각장애연구, 21, 111-120.

이미래, 황민아, 고선희(2017). 학령기 경계선급 지능 아동의 다의 동사 이해. 언어치료연구, 26, 55-65.

이병택(2002). 다의어 해소의 어휘과정에서 보이는 개인차: 숙련독자의 문맥의존적인 처리특성. 서울대학교 대학원 박사학위논문.

이승복, 이희란(2007). 단순언어장애아동의 단어정의하기-정의유형 분석을 중심으로. 언어치료연구, 16, 1-18.

정미란(2009a). 초등학교 3-6학년 읽기이해 부진 학생의 읽기이해력 예측 변인 탐색. 단국대학교 대학원 박사학위논문.

정미란(2009b). 초등학교 3-6학년 읽기이해부진 학생의 단어유추. 언어청각장애연구, 14, 275-287.

조명한(1997). 작업기억과 언어처리의 개인차. 한국심리학회지: 일반, 16, 18-39. 